\title{
India: Dabate on Job Reservation in Private Sector
}

\author{
Balwant Singh Mehta* \\ Institute for Human Development, New Delhi, India
}

*Corresponding author: Balwant Singh Mehta, Institute for Human Development, New Delhi, India, Email: balwant.mehta@ihdindia.org Submission: 漹 August 13, 2018 ; Published: 海 August 17, 2018

\section{Opinion}

Government of India introduced reservation to uplift the marginalised communities such as Schedule Caste (SC) and Schedule Tribe (ST) and Other Backward Class (OBC) in government jobs and education. These marginalised groups were excluded from mainstream development due to various socio-economic reasons in Indian society. However, the employment scenario has changed over the years after the economic reform with jobs in public sector has reduced and on the rise in private or corporate sector. Therefore, policy makers and others stakeholders are currently debating about the limited benefits of existing reservation to marginalised section of the society. On one hand, employment in public sector has stagnated around 17-18 million, on the other hand, private sector employment increased from 8.8 million to 12 million during the same period (Figure 1).

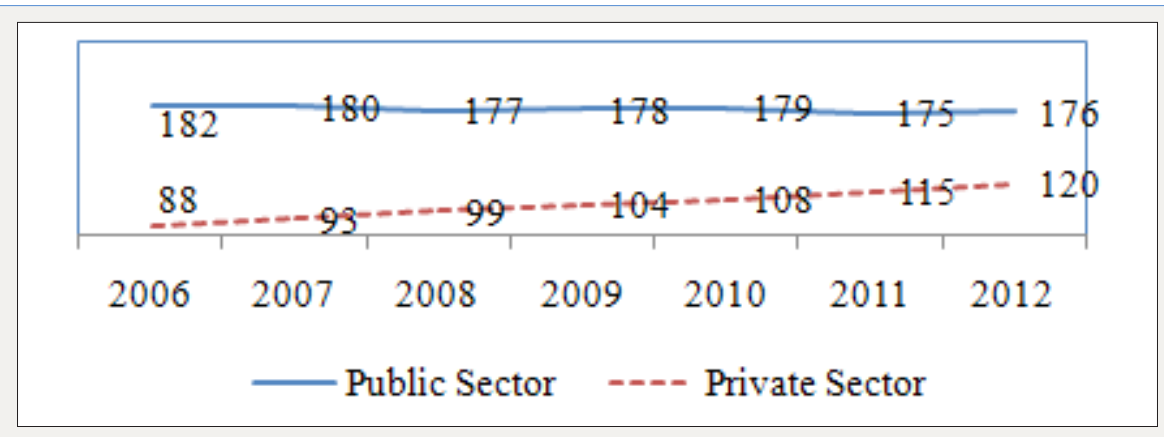

Figure 1: Public and private sector employment (in 000 thousands), Economic Survey [1].

The stakeholders such as political leaders, social activists, and people belong to marginalised sections and others are demanding about the extending current reservation policy to private sector jobs. However, the policy makers have disagreed on extending the job reservation in private sector, although they acknowledged about creation of more jobs in private sector. Instead, they emphasised more on 'equal opportunities in education and jobs' to every section of the society. The latest data shows that people from marginalised groups are 72 percent (ST, SC, and $\mathrm{OBC}$ ) compared to 28 percent of Upper caste (UC) or other groups in the total population in India, who are availing benefit of current reservation policy. In this context, comparing the two important indicators poverty and education level is worth examining, to know the current situation of marginalised groups relative to other group. The people belong to below poverty line considered as poor among the marginalised groups is significantly higher than the other groups.

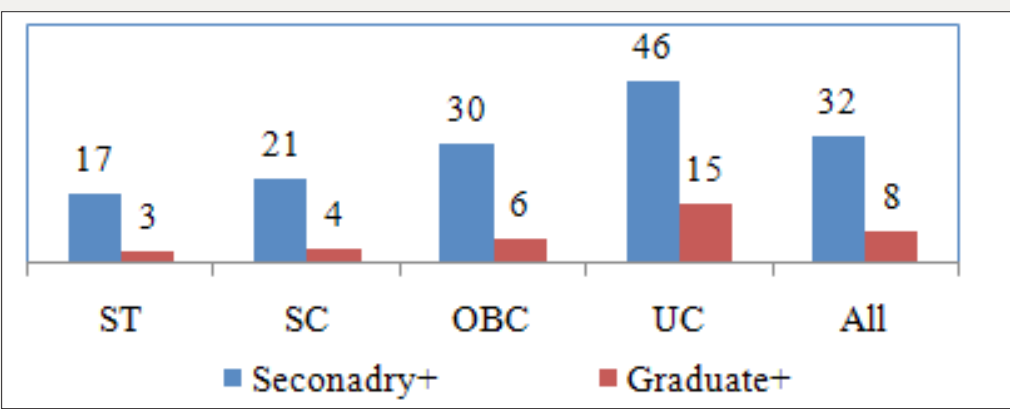

Figure 2: Educational level by social groups (in per cartage) [1]. 
The proportion of poor among marginalised groups 43 percent for SCs, 29 per cent for STs, and 21 per cent for OBC is higher than other groups 13 per cent. Similarly, irrespective of benefit of reservation in educational institutions, the educational level of marginalised group is lower than other groups. The participation in higher education (secondary and above) is 17 per cent for SCs, 21 per cent for STs, 30 per cent for OBC compared to 40 per cent for other groups (Figure 2). Their situation at graduated level is much worse with just 3 per cent of STs, 4 per cent of SCs and 6 per cent of OBCs are graduates and above qualified compared to 15 per cent of other groups. The decent level of education is one of the important indicators for access to decent jobs both in public and private sector in the country [1].

The current employment status of marginalised groups shows that they largely involved in low paid casual irregular jobs (Figure 3 ). While proportion of other groups or UC in regular or well paid jobs is 70 per cent, which is significantly higher than marginalised groups. Their participation in private sector jobs is also significantly less (10-15 per cent) compared to other groups (39 per cent) as presented in Figure 4. Although, over the years their participation in government jobs has increased due to reservation in government jobs, but only concentrated at low paid and skill jobs, as Desai \& Dubey [2] study showed that more than 60 per cent of the sweeper in central government ministers were from marginalised groups. Thorat \& Attewell [3] said that there is stereotyping in hiring of private sector jobs and marginalised groups faces discrimination at the start i.e. job application screening. However, the decomposition exercise using various socio-economic factors reveal that for private sector or better paid jobs, skill or education played a key role, which contribute 46 per cent compared to 5 per cent of their social groups Mehta [4]. Hence, there are people arguing both in favour of extending and against the job reservation to the private sector (Figure 4).

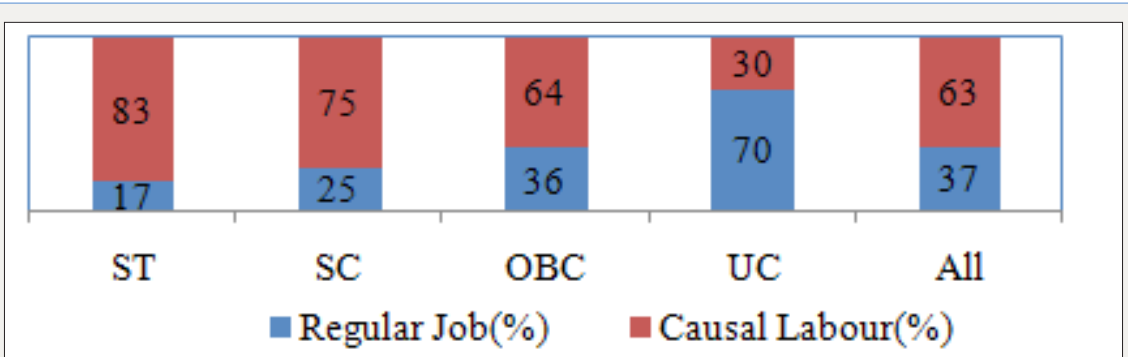

Figure 3: Employment status of workers by social groups [1].

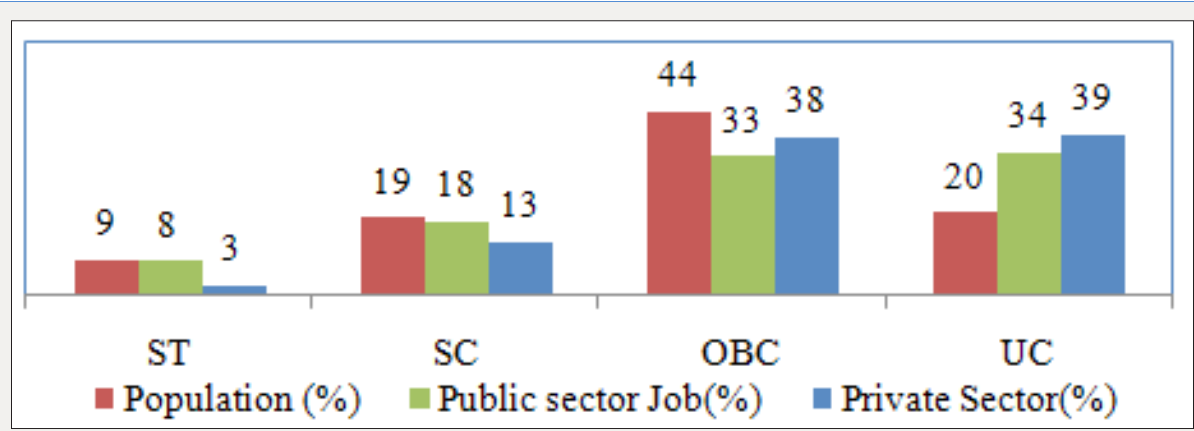

Figure 4: Share of Jobs in public and private sector by social groups.

People arguing about fair competition in a mixed economy like India, where both private and public sector are exits. The private sector is getting a lot of subsidies and concession from the government than why it should not have social commitment like public sector. However, the private sector association and other industry bodies are saying that this could reduce their productivity level due to lower skill level of hired workers on the basis of reservation policy imposed. They will not be able to survive in the current global competitive market as a result in loss of their profitability.

The government of India has introduced recently national skill mission to upgrade skill level and training to the youth for providing them productive employment. For success of any skill programme trainees should have at least some minimum level of educational qualification to understand the subject matter or course training.
But the educational qualification of marginalised groups is very poor with more than three-fourth of them either illiterate or less than secondary level educational qualification. So, the question is that how people from marginalised groups can avail the benefit of government's favourable initiatives with such poor literacy level, which can help them to be employed in well paid jobs both in public and private sector. There is need to facilitate private sector for helping children and youth belong to marginalised groups for their higher educational pursuit by providing them scholarship and other benefits. So, the can get high skill and well paid jobs in both public and private sector.

\section{References}

1. (2016) Economic Survey 2016-17, Ministry of Finance, Government of India, Oxford University Press, England. 
2. Desai S, Dubey A (2011) Caste in the $21^{\text {st }}$ century India: competing narratives. Econ Polit Wkly 46(11): 40-49.

3. Thorat S, Attewell P (2007) The legacy of social exclusion: A correspondence study of job discrimination in India. Economic and
Political Weekly 42(41): 13-19.

4. Mehta BS, Shree M (2017) Inequality across gender and social groups in India. Economic and Political Weekly 52(8). (c) (i) Creative Commons Attribution 4.0 International License

For possible submissions Click Here

Submit Article

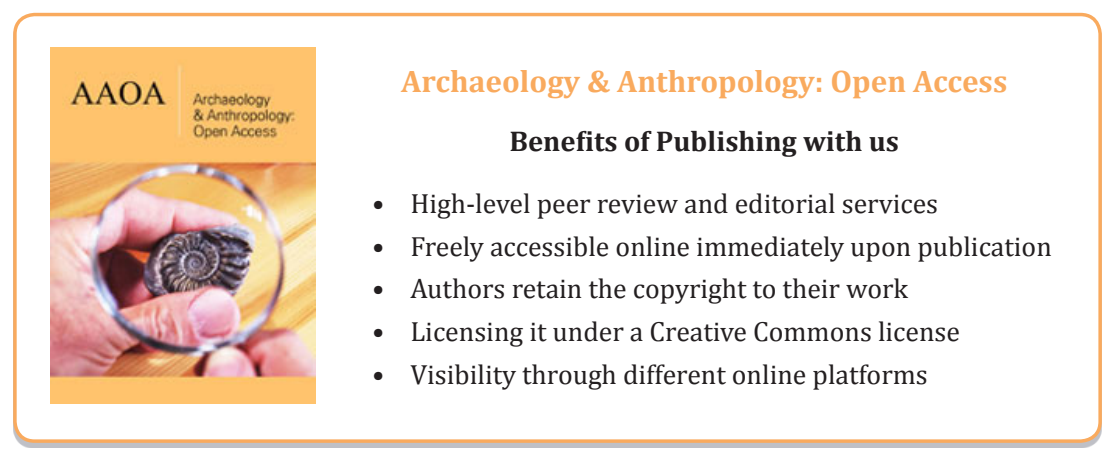

